\title{
Study on Mental Health for Students under Big Data Background
}

\author{
Zhen Huang \\ Shandong Women's University \\ Jinan, China 250300
}

\begin{abstract}
Recently, we are entering the age of big data. Big data applications greatly changed our life, bring great convenience to our life, and deeply affected the college education management mode, especially helping with aid-receiving student's psychological health care. Through this article focus on the real-time and coherent data analysis summary, from the evaluation feedback mechanism, the consciousness of big data professional training, a typical example of a positive guidance, privacy protection and other aspects. Comprehensive, by analyzing students' psychological, we can further explore the new ways to solve students' psychological security care mechanism, for helping students solve their psychological problems, in particular, maintaining their own psychological security.
\end{abstract} care

Keywords - the age of big data; assisted students; mental health

\section{INTRODUCTION}

At present, the world has entered "big data" with the characteristics of $4 \mathrm{~V}$ (Volume, Velocity, Value, Variety), which is characterized by large capacity, fast speed, Variety and Value. There is no uniform definition of big data. The definition of the McKinsey global institute for big data is a large scale to greatly in terms of access to storage management analysis, which is beyond the traditional ability range of data collection, database software tools or huge amounts of data. Nowadays, the development of big data era shows the following trends: the resource of data; Deep integration with cloud computing; Breakthroughs in scientific theory and technology. The establishment and management of data science become the core competitiveness, and the complexity of data ecosystem is also strengthened. The big data era provides new ways of service management for colleges and universities. This paper will discuss how to make use of big data to help care students' mental health.

\section{Psychological Profile of the Age of Big DatA AND THE STUDENT}

\section{A. Big Data Era Overview}

Big data is not in a certain time range with conventional software tools to capture, manage, and process of data collection, is a large scale to the acquisition, storage, management, analysis, well beyond the traditional scope of data collection, database software tools is the need to deal with the new model can have better decision-making, insight found mass force and the process optimization ability, high rate of growth and diversification of information assets[1]

Big data has four characteristics: massive data scale, rapid data flow, diverse data types and low value density.

\section{B. The Usefulness of Big Data Era for the Mental Health Care}

Big data has created great wealth in business, economics and other fields. In recent years, the influence of the big data has infiltrated all aspects of student life, according to a 201638 times China Internet development statistics report shows that college students' Internet population accounts for $11.5 \%$ of the total, including cell phone users reached 656 million, network has become an indispensable medium of undergraduate students [2]. Especially since the media such as QQ, micro letter, more and more students feel, with the help of the media platform express thought: psychological trend, the real-time data collection, you can become our timely first-hand information, analysis the students psychological understanding of the latest dynamic [3]. In addition, the educational administration system, library system, campus id, security system, financing system, labor system, the dormitory administrator system, post bar and other social networking platform to collect, share, huge amounts of data information will help us for students more psychological safety objective and scientific evaluation mechanism [4].

At the same time, as countries for each college student aid strength increasing, the scale of the aid-receiving students growing, as a special group, much attention has been paid to psychological security situation due to financial difficulties and sudden change of family environment influence in many ways, such as aid-receiving students relatively general students are more likely to suffer mental problem. Especially under the background of big data, helped by the students' psychological security and facing new challenges, and presents new characteristics, therefore, take advantage of the data processing, the era of big data sharing, positively seek help students set up the mechanism of psychological security care way has extremely important practical significance[5].

\section{THE PSYCHOLOGICAL PROFILE AND INFLUENCING FACTORS OF THE STUDENTS}

Aid-receiving students at present, the psychological situation is generally stable, but also exposed the corresponding 
problems, such as lack of aid-receiving students specialized data platform, timely aid-receiving students understand the psychological dynamics, aid-receiving students problems after screening, tracking return visit to lag, some students after the grant, unable to face difficult situation, produce inferiority, and other unhealthy psychological[6]; The students are mostly students of family difficulties and financial difficulties, such as the family and other external factors, psychological insecurity, weak psychological mechanism and so on.

\section{A. The School Is not Perfect for the Psychological Counseling of Students}

School for aid-receiving students psychological counseling system is not perfect, to a certain extent, does not favor the aidreceiving students psychological health care, specific performance is as follows: first, the lack of dedicated team psychological school, teacher shortage[7][8]; Second, the psychological health of the school education is monotonous and empty, the cases are too few, the relevant teaching contents are obviously empty, for the students, there is no specific significance; Third, the students are not aware of the relevant state aid policies. Lack of resource information source, channel is not smooth, to a certain extent; it is not conducive to students' psychological security and stability care.

\section{B. The Students Are Vulnerable to Psychological Security Care}

Some students don't pay attention to their own inner world, and not timely communication with teachers and classmates, for their own mental health consciousness of lack of the necessary adjustments, after the changes and difficulties, more to want to put on the outside, the lack of internal review and self-strengthening consciousness, lead to miss the in the mind to maintain the best time [9].

\section{The Systematic Support of Students' Psychological Care Mechanism Is Inadequate}

Lack of real-time, sharing, continuous aid-receiving students psychological data, statistical analysis, trend and case integration project database, realize the combination of various data, extended use, provide decision-making consultation based on powerful data analysis[10]. We will integrate all aspects of data to establish a scientific and objective evaluation mechanism for psychological status, pay attention to the preservation and safety of data, and provide psychological security care technology for students.

\section{Lack of Positive Typical Case Guidance}

Student role models are powerful, and students are guided by positive role models. Although many of the students are suffering from family changes and economic difficulties, they are still able to achieve success in all aspects, such as academic success, with tenacious will and optimistic spirit. In reality, however, there is a dearth of similar positive examples.

\section{The Students' Mental Health Maintenance Path}

Student role models are powerful, and students are guided by positive role models. Although many of the students are suffering from family changes and economic difficulties, they are still able to achieve success in all aspects, such as academic success, with tenacious will and optimistic spirit. In reality, however, there is a dearth of similar positive examples.

\section{A. Help Students to Maintain Consciousness of Mental Health}

We will continue to improve the system of mental health maintenance for students, and pay attention to the conscious awareness of students' mental health maintenance.

First, increase the aid-receiving students mental health maintenance money, technology, personnel, establish aidreceiving students psychological health maintenance specialized team, training teachers, a professional theory knowledge, have a professional practice skills combining modern teaching facilities to optimize learning knowledge. Aid-receiving students second, building maintenance mechanism of mental health education courses and programs, further perfecting the aid-receiving students' mental health education curriculum system of maintenance, and have corresponding reasonable evaluation mechanism. Third, rich recipients in the form of students' psychological health education, to strengthen the timeliness and let the students to the theory of mental health have a deep understanding of knowledge, combined with courses to be perfect, teachers, teaching, practice and practice, achieve aid-receiving students' psychological health maintenance "chain". Ensure smooth communication channels. It can also make full use of Internet and big data technology to simulate the application of simulation teaching, and improve the learning experience of students' mental health maintenance [11].

\section{B. Construction Statistical Analysis, Trend Direction, Case Integration and Other Thematic Database}

Based on the research of the existing problems, and find a solution to the countermeasures, such as real-time, sharing, continuous aid-receiving students psychological data, statistical analysis, trend and case integration project database, realize the combination of various data, extended use, provide decisionmaking consultation based on powerful data analysis[12]. For the students with potential risks of mental health, the students who have the potential risk of mental health should pay attention to the data in a timely manner and conduct active guidance. Aid-receiving students psychological health maintenance need to insist for a long time and dynamic, make full use of big data era background, excavate the potential valuable clues of data completes the aid-receiving students mental health maintenance mechanism of perfect and development.

\section{Integrate the Data of Various Aspects}

The evaluation mechanism of the psychological state of the students' mental health is formed scientifically and objectively, and the evaluation mechanism is completed by means of scale, observation and conversation. Evaluation mechanism should be established based on the complete and effective data on dynamic library, pay attention to the preservation and security of data, provide the aid-receiving students psychological security maintenance technical support, etc., to establish realtime Shared psychological database, through the psychological 
analysis of database data, sharing, to form a coherent feedback timely and effectively mechanism; Pay attention to the educational system, scientific research system, labor system, dormitory, books, financial data, one cartoon comprehensive summary of data, such as reduction of students learning, living, psychological emotion, provide the basis for comprehensive science data evaluation. According to law, completes the freshman orientation, students, graduates and alumni messenger key nodes, form a coherent data sharing, summary through the data analysis, the formation of early warning mechanism, to do a good job of students' psychological health care recipients.

\section{Reinforce Positive Case Publicity}

First, invite the outstanding representatives of the students to give lectures, and communicate with each other in a face-toface manner, so as to better understand the experience of the students who are helping them. According to their practical problems, they can also track and reply in time. Aid-receiving students second, schools and government set up a good public opinion direction, especially for aid-receiving students heart inferiority, the status quo, college students should face up to the relevant domestic misfortune, to face the problems in the process of growth[13]. Aid-receiving students inclusive fail, take more family responsibilities and academic pressure, want to let them to face the problems of its own, life is not plain sailing, success or failure is influenced by many factors, a more positive view of the aid-receiving students in colleges and universities need to society, the psychological problems of rational real successful case of recipient. To create a favorable environment for helping the society to form a good help guide, to give students more respect, higher social status, and to work together to help students to maintain mental health.

\section{CONCLUSION}

Big data brings innovation opportunities to mental health education. It should fully explore and utilize the potential value behind the scattered and massive data of colleges and universities. By collecting and analyzing the daily attention of college students and constructing the database of life learning mode, it will greatly promote the maintenance of psychological security of such students. In the era of big data, in addition to improving students' awareness of information security, they should pay more attention to the important status of technology security. While making full use of the convenient sharing of big data resources, we should do a good job in protecting the psychological data privacy of students.

\section{ACKNOWLEDGMENT}

This paper is supported by the Shandong Women's University Safety Campus project (No.: 2017PAXY06).

\section{REFERENCES}

[1] Hunt J, Eisenberg D. Mental health problems and help-seeking behavior among college students[J]. Journal of Adolescent Health, 2010, 46(1), pp, 3-10.
[2] Mori S C. Addressing the mental health concerns of international students[J]. Journal of counseling \& development, 2000, 78(2), pp,137144.

[3] Kitzrow M A. The mental health needs of today's college students: Challenges and recommendations[J]. NASPA journal, 2003, 41(1), pp, 167-181.

[4] Manthorpe N S J. Responding to students' mental health needs: Impermeable systems and diverse users[J]. Journal of Mental Health, 2001, 10(1), pp, 41-52.

[5] Roeser R W, Midgley C. Teachers' views of issues involving students' mental health[J]. The Elementary School Journal, 1997, 98(2), pp, 115 133.

[6] Roberts R, Golding J, Towell T, et al. The effects of economic circumstances on British students' mental and physical health[J]. Journal of American College Health, 1999, 48(3), pp, 103-109.

[7] Miller M J, Yang M, Hui K, et al. Acculturation, enculturation, and Asian American college students' mental health and attitudes toward seeking professional psychological help[J]. Journal of Counseling Psychology, 2011, 58(3), pp, 346-351.

[8] Hyun J, Quinn B, Madon T, et al. Mental health need, awareness, and use of counseling services among international graduate students[J]. Journal of American College Health, 2007, 56(2), pp, 109-118.

[9] Andrews B, Wilding J M. The relation of depression and anxiety to life - stress and achievement in students[J]. British Journal of Psychology, 2004, 95(4), pp, 509-521.

[10] Andrews B, Wilding J M. The relation of depression and anxiety to life - stress and achievement in students[J]. British Journal of Psychology, 2004, 95(4), pp, 509-521.

[11] Storrie K, Ahern K, Tuckett A. A systematic review: students with mental health problems - a growing problem[J]. International journal of nursing practice, 2010, 16(1), pp, 1-6.

[12] Zivin K, Eisenberg D, Gollust S E, et al. Persistence of mental health problems and needs in a college student population[J]. Journal of affective disorders, 2009, 117(3), pp, 180-185.

[13] Hefner J, Eisenberg D. Social support and mental health among college students[J]. American Journal of Orthopsychiatry, 2009, 79(4), pp, 491497. 